\title{
An Exploratory Optimal Framework of Low Impact Development Measures Spatial Arrangement based on Source Tracking for Urban Flood Mitigation
}

\section{Wenchao Qi}

Tianjin University

Chao Ma (D mac_tju@126.com )

Tianjin University

Hongshi Xu

Zhengzhou University

\section{Zifan Chen}

Tianjin University

\section{Kai Zhao}

Tianjin University

Hao Han

Xi'an University of Technology

\section{Research Article}

Keywords: Low impact development, Regional relevance, Source tracking, Spatial arrangement, Urban flood model

Posted Date: March 23rd, 2021

DOl: https://doi.org/10.21203/rs.3.rs-350792/v1

License: (9) This work is licensed under a Creative Commons Attribution 4.0 International License. Read Full License

Version of Record: A version of this preprint was published at Water Resources Management on August 4th, 2021. See the published version at https://doi.org/10.1007/s11269-021-02915-2. 

.

An exploratory optimal framework of low impact development measures spatial arrangement based on source tracking for urban flood mitigation

Wenchao Qi ${ }^{1,2}$, Chao Ma ${ }^{1,2 *}$, Hongshi Xu ${ }^{3}$, Zifan Chen ${ }^{1,2}$, Kai Zhao ${ }^{1,2}$, Hao Han ${ }^{4}$

${ }^{1}$ State Key Laboratory of Hydraulic Engineering Simulation and Safety, Tianjin University, Tianjin 300072, China

${ }^{2}$ School of Civil Engineering, Tianjin University, Tianjin 300072, China

${ }^{3}$ School of Water Conservancy Engineering, Zhengzhou University, Zhengzhou, 450001, China

${ }^{4}$ State Key Laboratory of Eco-hydraulics in Northwest Arid Region of China, Xi'an University of Technology, Xi' an 710048, China

* Corresponding author: Chao Ma

E-mail addresses: mac_tju@126.com (C. Ma) 
Abstract: Urban areas are vulnerable to flooding as a result of climate change and population growth and thus rainstorm-induced flood losses are becoming increasingly severe. Low impact development (LID) measures are a storm management technique designed for controlling runoff in urban areas, which is critical for solving urban flood hazard. Therefore, this study developed an exploratory simulation-optimization framework for the spatial arrangement of LID measures. The proposed framework begins by applying a numerical model to simulate hydrological and hydrodynamic processes during a storm event, and the urban flood model coupled with the source tracking method was then used to identify the flood source areas. Next, based on source tracking data, the LID investment in each subcatchment was determined using the inundation volume contribution ratio of the flood source area (where most of the investment is required) to the flood hazard area (where most of the flooding occurs). Finally, the resiliency and sustainability of different LID scenarios were evaluated using several different storm events in order to provide suggestions for flooding predictions and the decision-making process. The results of this study emphasized the importance of flood source control. Furthermore, to quantitatively evaluate the impact of inundation volume transport between subcatchments on the effectiveness of LID measures, a regional relevance index $(R I)$ was proposed to analyze the spatial connectivity between different regions. The simulation-optimization framework was applied to Haikou City, China, wherein the results indicated that LID measures in a spatial arrangement based on the source tracking method are a robust and resilient solution to flood mitigation. This study demonstrates the novelty of combining the source tracking method and 
highlights the spatial connectivity between flood source areas and flood hazard areas. Further, the framework acts as a strategic tool for the effective spatial arrangement design of LID measures.

Keyword: Low impact development, Regional relevance, Source tracking, Spatial arrangement, Urban flood model

\section{Introduction}

Hydrological responses are significantly affected by interactions between the temporal and spatial variability of rainfall, and watershed characteristics. These interactions are extremely pronounced in urban areas, where runoff generation is quick because of the high degree of impervious cover (Cristiano et al. 2019). Thus, urban flood has become a global issue as the result of climate change, urbanization, and urban drainage infrastructure limitations (Duan et al. 2016; Tang et al. 2016; Wang et al. 2019; Valizadeh et al. 2019), thereby causing significant impacts on society, the economy, and the environment. Several trends indicate that urban flood hazard will only increase with time. First, as climate change has increased the extreme rainfall events, both by frequency and magnitude. An increase in extreme rainfall events, particularly high intensity short duration rainfalls, has been observed as of late (Willems et al. 2012). Climate change has been widely acknowledged as a serious issue because of its impact on urban areas in terms of changes in runoff (Ranger et al. 2011; Hallegatte et al. 2011). Second, the urban population is projected to will exceed $80 \%$ of the total population by 2030 (Salvadore et al. 2015), thereby exposing more people to flooding. Further, as urbanization is expanding to accommodate increasing populations, the transition of 
natural catchments into urbanized catchments causes urban flood through reduced infiltration and faster hydrological responses (Becker et al. 2018). Third, corresponding to the transformation of rural landscape into urban forms, an obvious relationship between local micro-climates and urban areas has developed. This relationship promotes the occurrence of urban flood. For example, the "urban heat island" effect, wherein urban areas have higher temperatures than surrounding regions, has been well proposed (Bentley et al. 2010). In some cases, "urban heat island" increases rainfall volume in regions downwind of urban areas. Without interference, the damage caused by flood globally may increase by up to a factor of 20 by the end of the century (Winsemius et al. 2016).

Impermeability and the rapid transportation of stormwater are both linked to a drastic reduction in the hydrologic function of the landscape, including infiltration and evapotranspiration result in typical consequences are high flow peaks, rapid runoff movement, and high frequency flooding. Low impact development (LID) measures, which is a storm management and non-point source pollution treatment technique, was first adopted in North America and New Zealand in the 1980s (Fletcher et al. 2015). It aims to control the runoff and pollution generated by storm events via a decentralized and small-scale source control to ensure that the development area is as similar as possible to the natural hydrological cycle. Furthermore, LID measure is an ecological technique that can easily realize urban stormwater collection and utilization. In particular, it emphasizes the on-site small-scale control of stormwater sources. For example, Hood et al. (2007) compared the effects of LID and traditional residential 
development, and the results found that LID lowered runoff volume, the runoff coefficient, peak discharge rate. It also indicated that the LID effect was even greater for smaller storms with shorter durations. Williams et al. (2006) compared four development alternatives for infiltration techniques and land preservation to indicate that LID measure is effective for small storms. LID planning and implementation for urban flood mitigation have thus been proposed as an indispensable component of urban stormwater management. Selecting a proper spatial arrangement of LID measures and placing them in the suitable location is crucial when designing LID measures spatial layout schemes under given investment constraint. As policymakers are concerned about how to achieve a positive multi-functional return, especially regarding the flood hazard aspects. Thus, there is an urgent need to reach a balance between economic issues and LID spatial allocation.

Some studies have indicated that scenario analysis methods for LID spatial arrangement design can address these concerns. Scenario analysis methods are driven by a set of influencing factors, wherein each planning scenario is designed based on certain prerequisites. For example, Liu et al. (2014) quantitatively assessed the flood peak flow reduction of Green Infrastructure (GI), and the results showed that integrated GIs spatial arrangement is more effective than single measure for flood mitigation. Gilroy et al. (2009) conducted a study to determine the impact of LID measures on reducing flooding. They indicated that flood reduction capacity of single LID measure is determined by the potential mechanism, and the spatial arrangement of the measure greatly affects the flood control effectiveness of multiple LID measures. However, the 
111 quality of scenario assumptions greatly influences the reliability of scenario analysis

112 (Urich, et al. 2014; Zischg, et al. 2017). In addition, the inability to identify all potential

113 scenarios, scenario analysis does not seek the most cost-effective solutions, which often

114 result in schemes far from pareto optimality (Liu et al. 2016; Xu et al. 2017).

115 The shortcomings of scenario analysis methods have led to many researchers to design LID measures spatial arrangement based on urban flood models coupled with

The constraint factors for optimization primarily involve three themes (Bakhshipour et al. 2019): (1) design objectives, such as the reductions in runoff and peak flow volume; stormwater management. The results indicated that in terms of cost-benefit ratio, implementing LID measures in upstream areas is the most effective approach. 
Optimization allows researchers to identify the optimal solution set from a large number of results. However, some research gaps remain. First, as an optimization model is a "black-box" approach, it lowers the confidence of city planners in the optimization results. Second, optimization often leads to non-unique solution sets. Third, previous studies mostly focused on coupled simulation-optimization methods, which normally require large computational burdens (particularly for two-dimensional flood modeling).

Thus, it is desirable to develop more efficient ways of conducting evaluations and future designs. In addition, traditional multi-objective evolution algorithms and scenario analysis methods can not determine the most effective spatial arrangement of the LID measures.

A city is a complex space formed by the interaction of multiple interoperable catchments, in which water is central to many of these interactions as it can be transported to different subcatchments via flood pathways. An obvious disconnect between the most effective locations for flood management investments and the locations where floods are most likely to occur. While researches exist regarding the selection of LID measures depending on a specific location, they usually obtain information regarding only one aspect of urban flooding such as traffic channel or infrastructure that may be at risk. There are few methods that link the root causes and potential impacts of flood problems to specific flood management interventions within existing urban systems. Therefore, identifying flood source areas (i.e., target locations that have the greatest impact on reducing flood hazards) can help guide the spatial priority of flood management measures. For this purpose, an exploratory analysis 
framework was proposed that aims to guide strategic decision-making for LID measures spatial arrangement designs. This framework involves a methodological process that combines flood mitigation strategies with spatial connectivity and uses the regional relevance index $(R I)$ to quantitatively measure the connection between flood source areas and flood hazard areas based on source tracking. By applying this framework to the urban watershed of Haikou (China), we identified the potential prioritization of LID spatial arrangement using source tracking data as a driving force. Furthermore, the framework output is especially important as it highlights the spatial connectivity between the flood source area (requiring most of the LID measures) and the beneficiary area (the areas where flooding is mostly reduced), thereby creating a basis for strengthening cooperation between these areas.

\section{Materials and methods}

\subsection{Overall framework}

The overall framework of the proposed method is illustrated in Fig. 1. First, an urban flood coupled model was established using a hydraulic model, hydrologic model, and source tracking module. Second, using a coupled model, the inundation volume was simulated under typical scenarios combining rainfall and tide level. Third, according to the inundation volume, the regional flood transfer coefficient $(A)$ and $R I$ were calculated for the drainage district. Finally, the spatial arrangement ratio for LID measures in different subcatments is determined by $A$ and LID investment ratio $(K I)$, and efficacy evaluation of adaptive LID measures are proposed for different LID scenarios. 


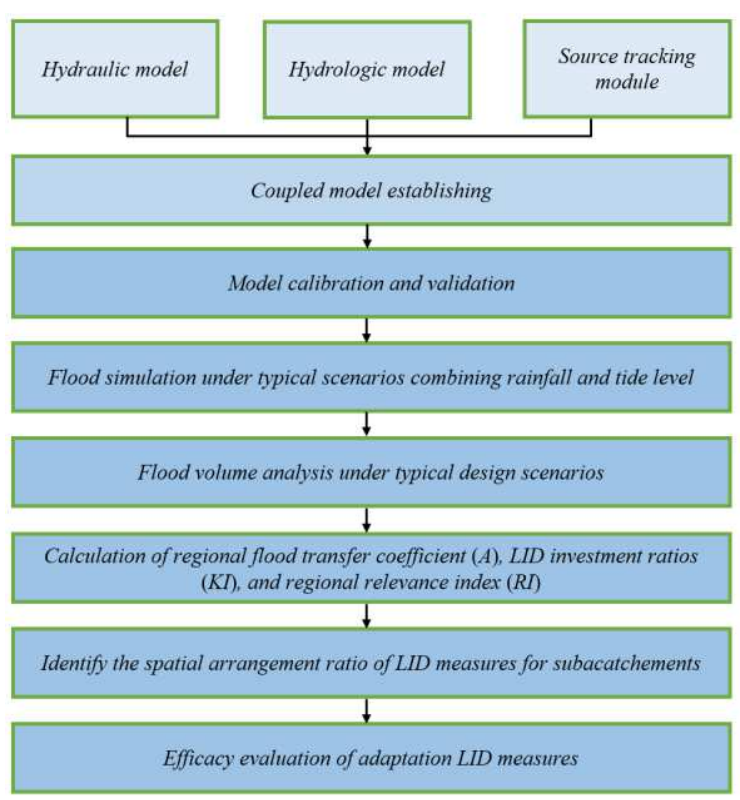

Fig. 1 Optimal framework of spatial arrangement of low impact development (LID) measures based on source tracking for urban flood mitigation

\subsection{Source tracking method based on PCSWMM model}

\subsubsection{Source tracking method}

The source tracking method depends on the relationship of a certain tracer with a specific host, wherein the origin of the host can be defined. In this study, tracers were employed to trace the entire process of stormwater runoff between different subcatchments in order to obtain the composition and source contribution of the inundation volume. According to the composition of the inundation volume in the hazard areas, an allocation scheme of LID measures can be developed to achieve the optimal urban flood mitigation strategy.

For example, during a storm event, the urban watershed (as shown in Fig. 2),

190 which consists of three subcatchments $(S 1, S 2$, and $S 3)$, can flood in response to rapid 191 runoff. The arrows represent the preferred direction of water flow. The runoff generated by subcatchment $S 1$ flows into $S 2$ and is mixed with the inundation volume generated 
by $S 2$. Subsequently, the inundation volume of $S 2$ divides into two parts. Some of the water flows into $S 3$, while the rest remains in $S 2$. Accordingly, the inundation volume of the flood hazard area is composed of the runoff of each subcatchment. We evaluated the runoff from subcatchments $S 1, S 2$, and $S 3$ using tracers A, B, and C, respectively, of constant concentration. According to the conservation of mass equation, the cumulative inundation volume from subcatchment $S 1$ in the hazard area expresses the ratio of the mass of tracer A to the corresponding concentration, as described in Eq. (1). Although the urban watershed is much more complex than the area in Fig. 2, the calculation method of the conservation relationship between inundation volume and tracer transfer is still effective, as given by Eq. (2).

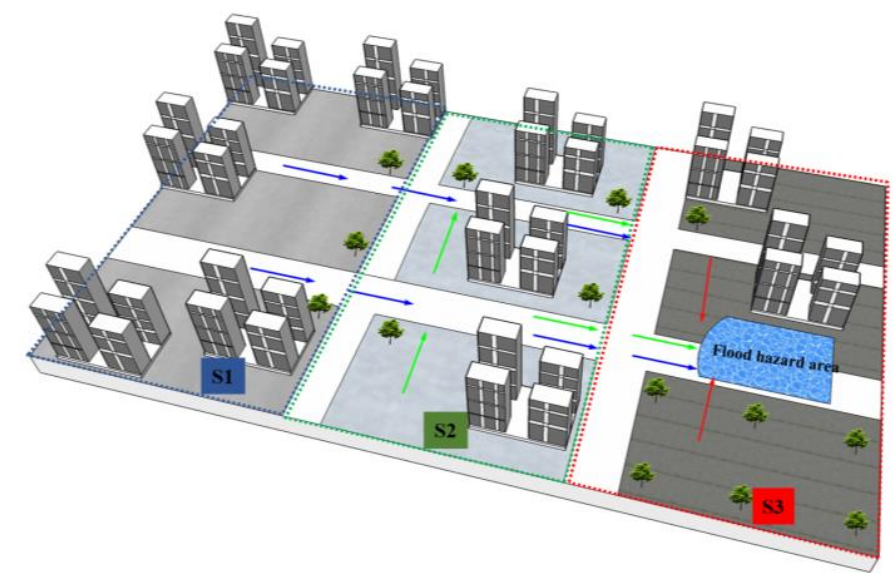

Fig. 2 Schematic diagram of the runoff source tracking process in urban watershed

$$
\left\{\begin{array}{l}
\frac{C_{1} V_{1}}{V_{1}+V_{2}+V_{3}}=C_{1}^{\prime} \\
\frac{C_{2} V_{2}}{V_{1}+V_{2}+V_{3}}=C_{2}^{\prime} \\
\frac{C_{3} V_{3}}{V_{1}+V_{2}+V_{3}}=C_{3}^{\prime}
\end{array}\right.
$$

where $C_{1}, C_{2}$, and $C_{3}$ are the initial tracer concentrations for subcatchments $S 1, S 2$, and $S 3$, respectively, which are constant values. $C_{1}{ }^{\prime}, C_{2}{ }^{\prime}$, and $C_{3}{ }^{\prime}$ are the concentrations of tracers in the flood hazard areas, and $V_{1}, V_{2}$, and $V_{3}$ represent the amount of inundation 
volume contributed by the three subcatchments (i.e., flood source areas) to the flood hazard areas, respectively.

$$
\left\{\begin{array}{l}
\frac{C_{1} V_{1}}{V_{1}+V_{2}+\cdots \cdots+V_{n}}=C_{1}^{\prime} \\
\frac{C_{2} V_{2}}{V_{1}+V_{2}+\cdots \cdots+V_{n}}=C_{2}^{\prime} \\
\cdots \cdots \cdot \\
\frac{C_{n} V_{n}}{V_{1}+V_{2}+\cdots \cdots+V_{n}}=C_{n}^{\prime}
\end{array}\right.
$$

where $C_{1}, C_{2}, \ldots \mathrm{C}_{\mathrm{n}}$ are the initial tracer concentrations for subcatchments $S 1, S 2, \ldots . S n$,

213 which are constant values. Meanwhile, $C_{1}{ }^{\prime}, C_{2}{ }^{\prime}, \ldots C_{n}{ }^{\prime}$ are the concentrations of tracers

214 in flood hazard areas, and $V_{l}, V_{2}, \ldots . V_{n}$ represent the amount of inundation volume contributed by the $1-n$ subcatchments (i.e., flood source areas) to the flood hazard areas, respectively.

\subsubsection{PCSWMM}

The PCSWMM combines SWMM 5 and GIS to provide a complete package for one-dimensional and two-dimensional analyses of stormwater modeling in urban watersheds (Tillinghast et al, 2012; Ahiablame et al, 2016; Xu et al 2018). The PCSWMM can accurately simulate unsteady two-dimensional surface flow above ground via two-dimensional floodplain modeling. The one-dimensional conduit and two-dimensional floodplain models were integrated by using the orifice connection method (Xu et al 2018). The hydraulic simulation calculation of drainage conduit was performed by adopting the dynamic wave method. In general, the drainage network system and water supply network form a set of urban water simulation systems. The basic principles of the model are the continuity and momentum equations as follows 


$$
\begin{gathered}
\frac{\partial A}{\partial t}+\frac{\partial Q}{\partial l}=0 \\
\frac{\partial Q}{\partial t}+\frac{\partial\left(Q^{2} / A\right)}{\partial l}+g A \frac{\partial H}{\partial l}+g A S_{f}+g A h_{L}=0
\end{gathered}
$$

where $A$ represents the cross-sectional area $\left(\mathrm{m}^{2}\right), l$ represents the distance along the conduit (m), $Q$ represents the flow rate $\left(\mathrm{m}^{3} / \mathrm{s}\right), t$ represents time (s), $H$ represents the pressure head (m), and $h_{L}$ represents the local energy loss/unit length conduit (m), $S_{f}$ represents the friction slope, $g$ represents the gravitational acceleration $\left(\mathrm{m} / \mathrm{s}^{2}\right)$.

In the PCSWMM, water quality routing within the conduit links and nodes assumes that the behavior of a continuously stirred tank reactor, and the concentration of a constituent exiting the conduit at the end of a time step is determined by integrating the conservation of mass equation, using average values for quantities that might change over time, such as the flow rate and conduit volume (CHI 2014). In this study, the event mean concentration (EMC) washoff model in the PCSWMM was adopted to generate a tracer source with a constant concentration. The EMC model is described by Eq. (5). Because the tracer only distinguishes the inundation volume, the tracer concentration settings in different subcatchments are the same. In the EMC model, the generation and disappearance of tracers occurs synchronously with the runoff process, and the total mass of the tracers is proportional to the cumulative runoff. In addition, the total mass of the tracer remains constant even though its concentration and spatial distribution changes during flow movement. Within the PCSWMM, the grid inundation

248 volume and tracer concentration processes can be obtained, and the inundation volume transfer process can be calculated using Eq. (2). 


$$
E M C=\frac{\int_{0}^{T} C_{t} Q_{t} d t}{\int_{0}^{T} Q_{t} d t}
$$

251 where EMC is the event mean concentration $(\mathrm{mg} / \mathrm{L}), T$ is the total runoff time, $C_{t}$ is the

252 pollutant concentration $(\mathrm{mg} / \mathrm{L})$, which varies with runoff time, and $Q_{t}$ is the runoff flow $253(\mathrm{~L} / \mathrm{s})$, which varies with runoff time.

\subsection{Adaptive LID spatial arrangement scheme}

\subsubsection{Quantifying the regional relevance}

The inundation volume contribution from the source area can be quantified using

the source tracking data. If the inundation volume in the hazard area comes from

multiple subcatchment runoffs, then the regional relevance is strong. Conversely, if the inundation volume comes from a smaller number of subcatchments, the regional relevance is weak. To quantify regional relevance, the regional relevance index $(R I)$ was developed to determine the importance of inundation volume transfer between

flood source and hazard areas during urban flood mitigation. The following method can be adopted to quantify the $R I$ for coastal cities. First, the regional flood transfer coefficient $(A)$ is calculated as follows:

$$
A_{i, j}=\frac{\sum_{t=0}^{t=n}\left(V_{i, j}\right)_{t}}{\sum_{t=0}^{t=n}\left(W_{i, j}\right)_{t}}
$$

where $V_{i, j}$ and $W_{i, j}$ are the transferred and generated inundation volumes, respectively, in an urban watershed under different combinations of rainfall and tide levels. $i$ and $j$ represent the design return periods of the rainfall and tide levels, respectively, and $t$ represents the time step of the flood simulation. 

and tide levels do not coincide, and the revision can be resolved in two cases.

(1) Regarding rainfall, the following revision should be included:

$$
C_{1}=\left(A_{1,1}+A_{1,2}+\cdots \cdots A_{1, n}\right) / n
$$

where $A_{l, 1}, A_{l, 2} \ldots A_{l, n}$ are calculated using Eq. (6) when the cumulative rainfall volume is $h_{l}$ (the minimum design rainfall volume), and the cumulative tide level changes from $z_{1}$ (the minimum design tide level) to $z_{n}$ (the maximum design tide level). Further, $\beta$ represents the unit change in rainfall, $p_{i, j}$ represents the revision value of $A_{i, j}$ in the rainfall changes, and $p_{1}$ is the average revision value under different combinations of rainfall and tide levels.

(2) Regarding tide level, the revision is defined as follows:

$$
C_{3}=\left(A_{1,1}+A_{2,1}+\cdots \cdots A_{n, 1}\right) / n
$$

$$
C_{4}=\left(A_{1, n}+A_{2, n}+\cdots \cdots A_{n, n}\right) / n
$$$$
\gamma=\frac{C_{4}-C_{3}}{z_{n}-z_{1}}
$$ 


$$
\begin{cases}q_{i, j}=A_{i, j}-\gamma\left(z_{j}-z_{i}\right) & i<j \\ q_{i, j}=A_{i, j} & i=j \\ q_{i, j}=A_{i, j}+\gamma\left(z_{i}-z_{j}\right) & i>j\end{cases}
$$

$$
q_{1}=\frac{\sum_{i=1}^{n} \sum_{j=1}^{n} q_{i, j}}{n^{2}}
$$

where $A_{1,1}, A_{2,1} \ldots \ldots A_{n, 1}$ are calculated using Eq. (6) when the cumulative tide level value is $z_{l}$ (the minimum design tide level), and the cumulative rainfall volume changes from $h_{l}$ (the minimum design rainfall volume) to $h_{n}$ (the maximum design rainfall volume). In addition, $\gamma$ represents the unit change in design tide level, $q_{i, j}$ represents the revision of $A_{i, j}$ in the design tide level changes, and $q_{1}$ is the average revision value under different combinations of rainfall and tide levels. Thus, the $R I$ is determined as follows:

$$
R I=\frac{q_{1}+p_{1}}{2}
$$

\subsubsection{Spatial arrangement ratio for LID measures}

Using the urban flood model, the inundation volume of each subcatchment can be calculated under different combinations of rainfall and tide levels. Further, the inundation volume contribution from the source area can be quantified based on the source tracking data. Then, the scale of the LID measures in different subcatchments is determined according to the ratio of each subcarchment's inundation volume contribution to the flood hazard area, which indicates that LID measures in larger innundation volume contribution areas have larger area ratios. The inundation volume contribution ratios of different subcatchments to the flood hazard area are determined as the investment ratio of the LID measures. This means that the inundation volume 
contribution proportion of each subcatchment to the flood hazard area is equivalent to the investment proportion of LID measures in each subcatchment. Eq. 6 can be used to calculate the $A$ under different return periods of rainfall at certain tide levels. The rainfall and tide level values with the maximum $A$ were used as inputs for the flood model to calculate the LID investment ratios $(K I)$ of different subcatchments. To reduce the flood risk of the entire study area, we defined the flood hazard area as the entire study area. The following method can be adopted to quantify the flood contribution ratio and:

$$
K I_{k}=\left(\frac{\sum_{t=0}^{t=n}\left(T_{i, j}\right)_{t}}{\sum_{t=0}^{t=n}\left(W_{i, j}\right)_{t}}\right)_{k}
$$

where $\left(T_{i, j}\right)_{k}$ is the inundation volume contribution produced by the subcatchment $k$ to calculated using Eq. 6.

A comprehensive cost and benefit analysis is required to determine the LID allocation. In this work, the benefits can be defined as inundation volume reduction due to implementation of flood mitigation strategies. Based on the source tracking method,

LID investment in each subcatchment was determined by the inundation volume contribution ratio of the source area to the hazard area, especially within strict budgetary constraints. 
(19)-(21) were adopted to identify the urban flood mitigation plans at a budget constraint.

$$
\begin{gathered}
C_{k}=C_{\text {total }} \times K I_{k} \\
C_{k}=\sum_{i=1}^{N} P_{k} \times C_{P}
\end{gathered}
$$

where $P_{k}$ is the area of the LID measures in subcatchment $k$, which was retrofitted with the LID measure, $C_{p}$ is the cost of unit area of the LID measure, and $C_{\text {total }}$ represents the total implementation investment of the flood management strategies. Eq. (21) describes the reduction in peak flow as a result of the LID solution compared with existing or predevelopment conditions.

$$
R=100 \times\left(\frac{V_{\text {Before }}-V_{\text {Affer }}}{V_{\text {Before }}}\right) \%
$$

where $V_{\text {Before }}$ is the change in peak inundation volume associated with the designated storm event, and $V_{\text {After }}$ is the peak flow volume after the implementation of flood mitigation measures. The resilience of each optimized scheme with different flood mitigation strategies was evaluated using the indicator $R$.

\section{Case study}

\subsection{Coupled urban flood model with source tracking method in Haikou City}

\subsubsection{Study area}

The main districts of Haikou City (Fig. 3) were selected as the study area. The urban watershed is located in the north of the Hainan Province, which is adjacent to the Qiongzhou Strait. The land use types in the main districts of Haikou City are mainly homes, roads, and buildings, resulting in a high ratio of impermeable areas. The annual 
average temperature and rainfall are $24.3{ }^{\circ} \mathrm{C}$ and $2067 \mathrm{~mm}$, respectively, which is a typical of tropical oceanic monsoon climate. The study area is vulnerable to urban flooding because of its high population density and flat terrain. For example, the occurrence of typhoon "Rammasun" during July 17-19, 2014, resulted in heavy rainfall on July 18, causing eight deaths and losses worth nearly 9 billion yuan.
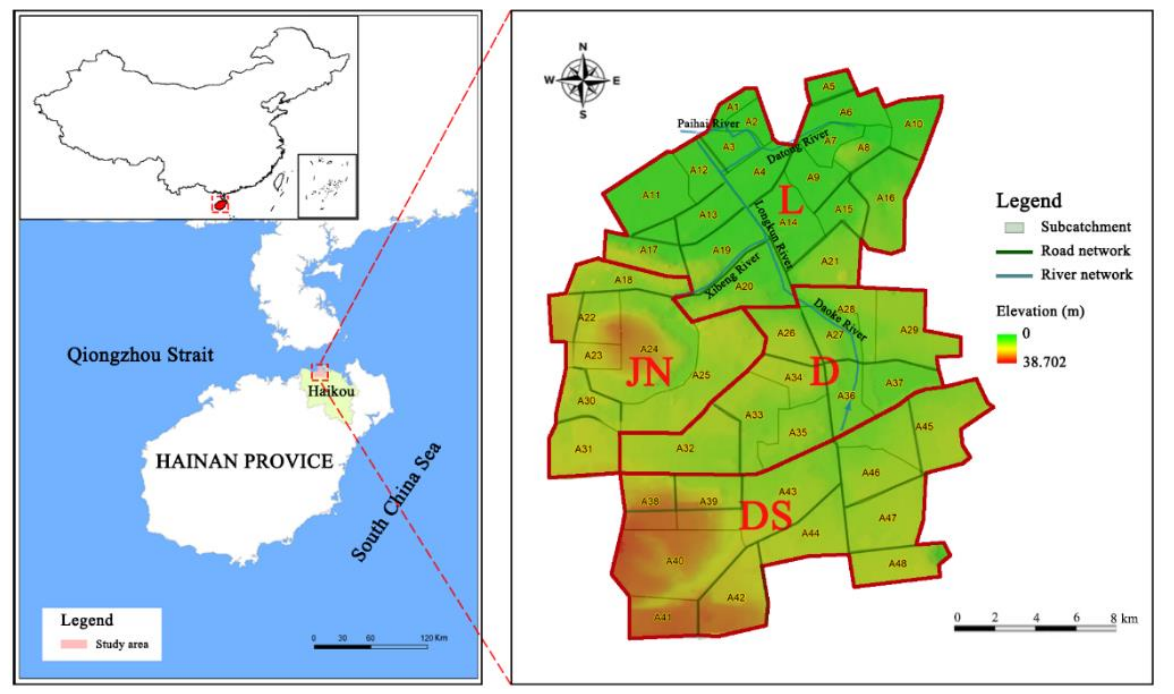

Fig. 3 Study area and sewer system distribution

\subsubsection{Establishing coupled model in Haikou City}

The data adopted for the urban flood model included rainfall, tide level, digital elevation model data, river data, and pipe network data, which were provided by the Haikou Municipal Water Authority. The urban flood model (Fig. 4) comprised 4401 links, 4563 nodes, 4 catchments, and 48 subcatchments. The subcatchment areas ranged in size from 14.76 ha to 136.35 ha. The total contributing area of the subcatchments was 2770.84 ha, of which 2042.93 ha was classified as impermeable and 727.91 ha as pervious. A recorded historical extreme precipitation event that occurred during July 17-19, 2014 resulted in a heavy flood hazard. Based on the measured rainfall data from 1974 to 2012 derived by the Haikou Station, the rainfall and tide level distributions (Fig. 

years, and 20 years were adopted as model inputs to analyze the flood response. coefficient value in PCSWMM was set to be the same for all subcatchments, and other parameter values were set to 0 .

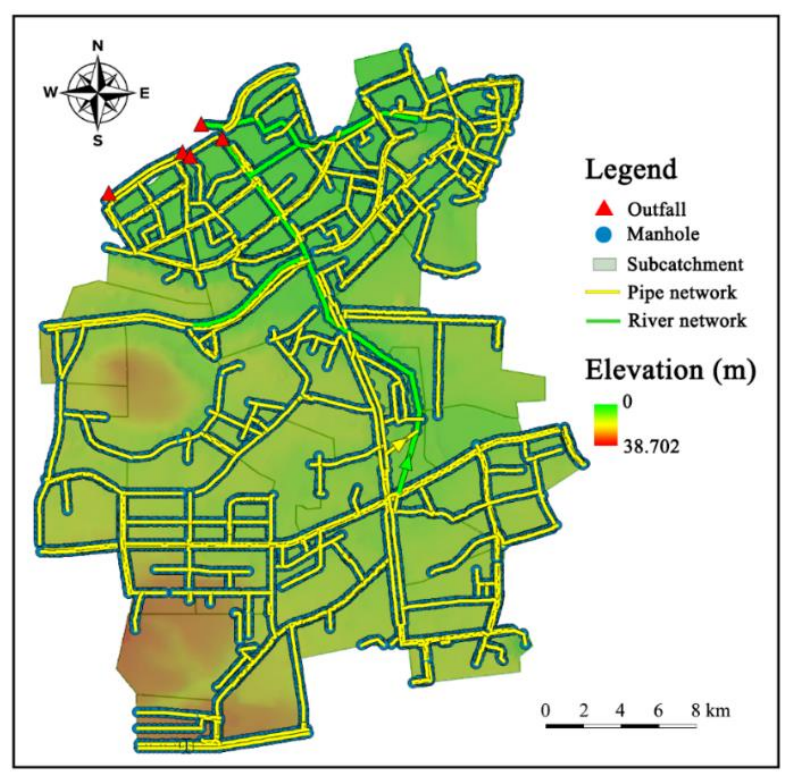

Fig. 4 Urban flood model establishing of study area based on the PCSWMM

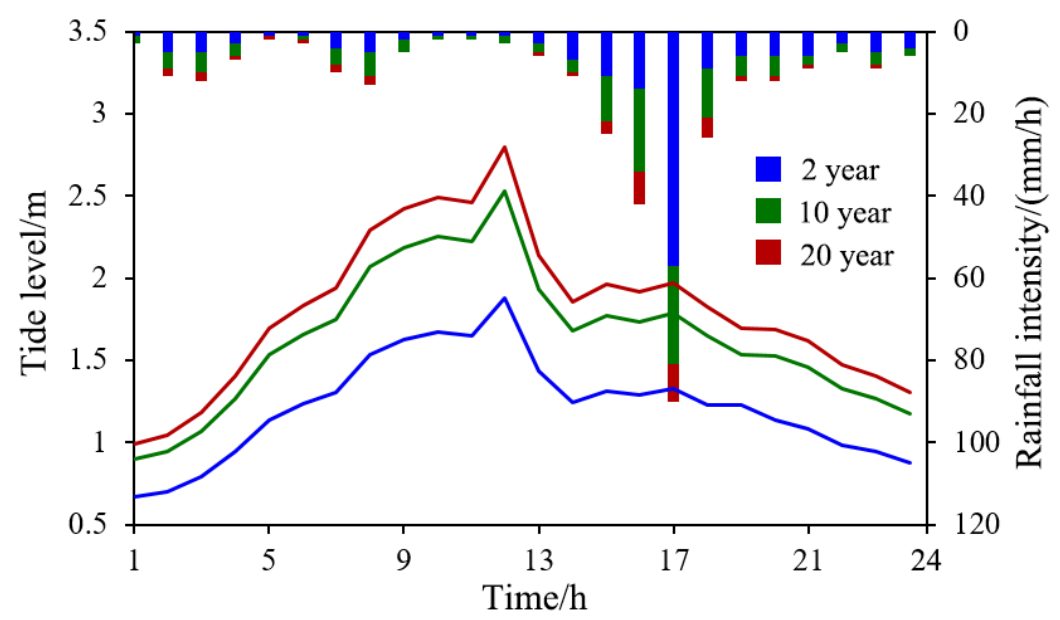




\subsubsection{Model calibration and validation}

The parameters of the urban flood coupled model established by PCSWMM were

380 calibrated by trial and error method. The Nash-Sutcliffe efficiency (NSE) index was used to measure the goodness of fit between the observation and simulation inundation depth values to evaluate the accuracy of the coupled model. In this study, the calibration inundation data were acquired during the typhoon "Rammasun" event. The comparison of simulated and measured inundation depth is shown in Figure 6. The observation locations are shown in Figure 7. The error between the observation and simulation values was less than $0.1 \mathrm{~m}$, and the NSE value was 0.844 . When the NSE value is greater than 0.5, the simulation results are satisfactory (Ahiablame et al. 2016). Hence, the coupled model is feasible and can be used to simulate a given flood scenario.

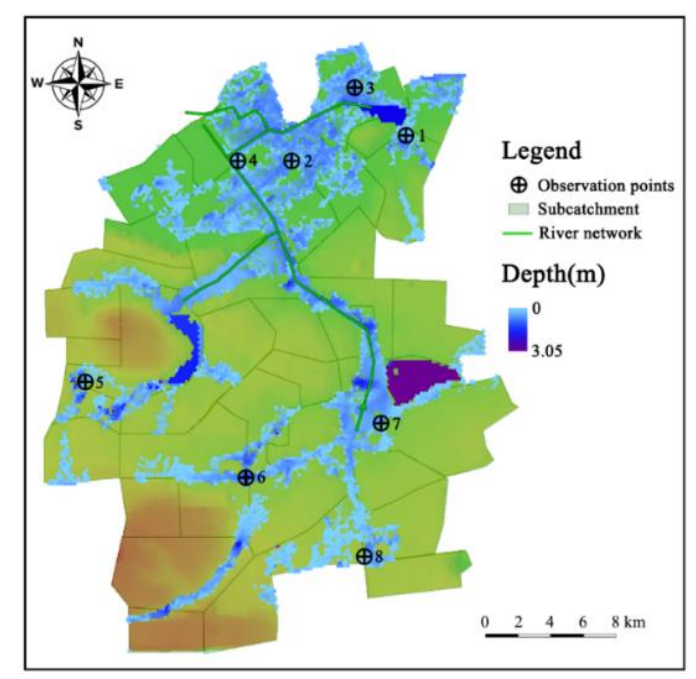

Fig. 6 Simulation flood during the "Rammasun" typhoon storm event in July 2014 


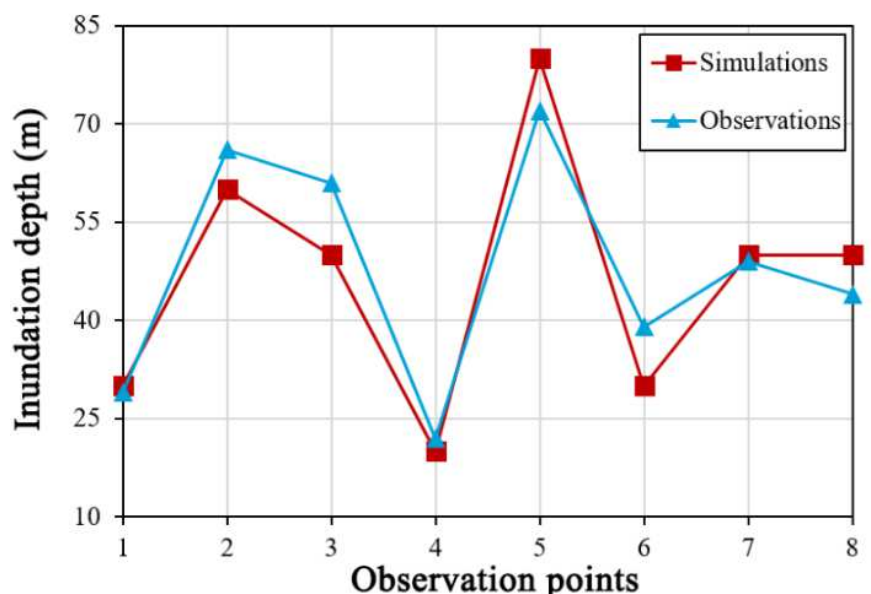

392 Fig. 7 Calibration of the PCSWMM

\subsection{Flood simulation in compounding rainfall and storm tide events}

The total inundation volumes, which can numerically reflect holistic severity, were

obtained during the simulation period. Based on source tracking method, the inundation

volume source of the entire study area is divided into 4 catchments (namely, L, JN, D,

and DS), wherein the related inundation volume process is shown in Fig. 8. It shows

that the contribution ratio of the source inundation volume in the catchment varied. For

example, when the return periods of rainfall and tide level were both set to 20-year, the

peak inundation volume contribution ratios of the catchments $\mathrm{L}, \mathrm{JN}, \mathrm{D}$, and DS were

$28.90 \%, 40.44 \%, 11.32 \%$, and $19.34 \%$, respectively. Hence, regarding the flood

disaster reduction strategies, it is necessary to focus on the source flood control of catchments JN and L.

In addition, the design values of rainfall and tide levels also affected the contribution ratio. For example, during the compound storms of 2-year rainfall with 2year, 10-year, and 20-year tide, the inundation volume contribution ratios of catchment JN were $53.91 \%, 53.33 \%$, and $51.35 \%$, respectively. Furthermore, the inundation 
2-year tide period with compound rainfall periods of 2-year, 10-year, and 20-year, respectively. These results indicate that, compared with the tide level, change in rainfall has a greater impact on inundation volume generation in the flood source area of catchment JN.

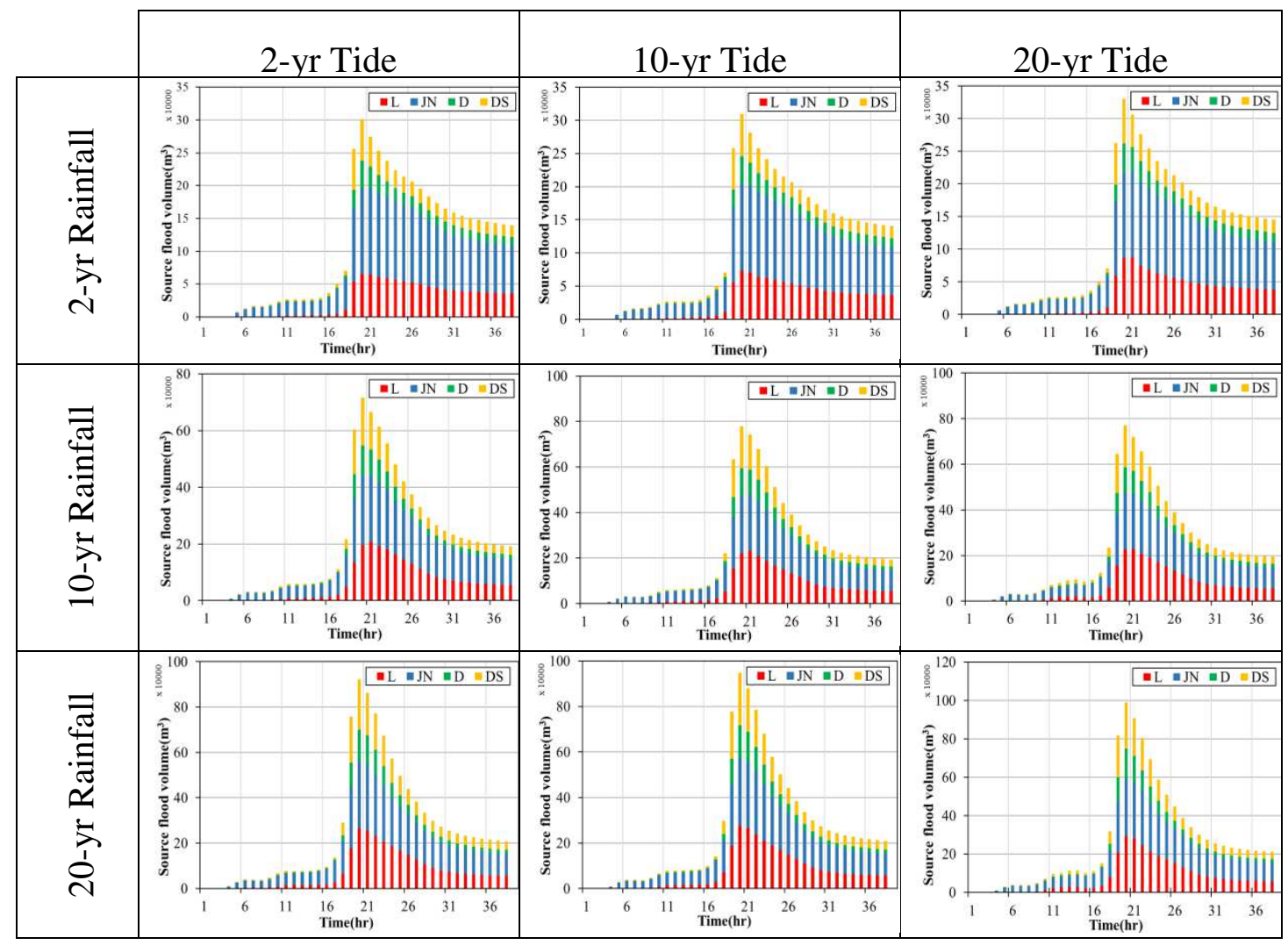

Fig. 8 Diagram of flood source area inundation volume contribution to hazard area under the combined impact of storm tides and heavy rainfall

\subsection{Quantification analysis of regional relevance}

An urban flood model was used to simulate flood processes under the combined impact of storm tides and heavy rainfall, wherein source tracking data were used to determine the source of flooding in a disaster area. The regional flood transfer coefficients calculated using Eq. (6) are listed in Table 1. The results indicate that the regional flood transfer coefficient increases with increasing rainfall return period and 
tide level. Specifically, for a return rainfall period of 2 years with 2 years, 10-year, and 20-year tide level return, the values of $A$ were $0.347,0.349$, and 0.352 , respectively. Further, at a return tide level period of 2 years, and return rainfall periods of 2 years, 10 years, and 20 years, the values of $A$ were $0.347,0.368$, and 0.392 , respectively. These results show that, compared with tide level, rainfall change has a greater impact on inundation volume generation in the regional flood transfer coefficient. the RI of the study area was found to be 0.375 , indicating that $37.5 \%$ of the inundation volume in the study area realized cross-regional transfer under stormwater events. This emphasizes the importance of source flood control in urban flood mitigation strategies.

Table 1 Regional flood transfer coefficients $(A)$ under combined storm tide and heavy

432 rainfall periods

\begin{tabular}{cccc}
\hline $\begin{array}{c}\text { Design Return } \\
\text { period }\end{array}$ & 2-yr design rainfall & 10-yr design & rainfall \\
\hline 2-Yr design tide & 0.3474 & rainfall & 0.3922 \\
level & & 0.3685 & \\
10-Yr design tide & 0.3493 & & 0.3934 \\
level & & 0.3844 & \\
20-Yr design tide & 0.3522 & 0.3889 & 0.3994 \\
level & & & \\
\hline
\end{tabular}

\subsection{Simulation scenarios}


storage as the water slowly penetrates into the underlying soil, the water is stored in a highly permeable matrix. The cost of implementing flood mitigation technologies varies considerably based on certain system specifications, soil type, and the location of implementation. Therefore, this study selected a representative cost of $194 \mathrm{yuan} / \mathrm{m}^{2}$ for installing permeable pavement (Hong et al. 2020). The total LID cost was selected to be 1 billion yuan, which is equivalent to a two-year government investment in a single pilot area of the "Sponge city" program construction in China.

A series of scenarios were explored to determine the placement of LID solutions for various storm events and budget constraints in main districts of Haikou City. Moreover, the analysis explored the varying limitations of the budget for effective stormwater control. Considering the essential difference between the flood source and flood hazard areas, two modes of intervention were designed:

A1-Without interventions, reflecting the actual state of flooding in the urban watershed.

A2-Local control interventions based on the inundation volume ratio of the flood hazard area.

A3-Source control interventions based on the inundation volume ratio of the flood source area to the flood hazard area.

Because of investment constraints, policymakers should allocate LID measures effectively to alleviate flooding. Hence, a spatial arrangement framework with the ability to mitigating the inundation volume was proposed to determine the optimal layouts of LID measures. In the spatial arrangement framework, the objective is to 
mitigating the inundation volume in the watershed within the budget constraints under

458 the worst designed storm. The use of LID measures is considered in the allocation

459 framework by dividing the catchments into subcatchments to determine the LID ratios

460 of each subcatchment.

461 According to the three LID measure scenarios, different spatial arrangement

462 schemes were developed. The A2 scenario is based on flood hazard area control,

463 wherein the ratios of the LID measure investment in four catchments are equivalent to

464 the ratios of inundation volume of each catchment to the inundation volume of the entire

465 study area. Meanwhile, the A3 scenario is determined by flood source area control,

466 which is based on source tracking data, wherein the inundation volume of the entire

467 study area is distinguished by the source of inundation, and the source inundation

468 volume contribution ratios of the four catchments to the study area are determined to

469 be the investment ratio of the LID measures in each catchment. Each scenario was

470 simulated during the compound storm of 20-year rainfall with 20-year tide (designing

471 scenario under maximum $A$ value). The LID measures and the spatial arrangement

472 ratios in scenarios $\mathrm{A} 2$ and $\mathrm{A} 3$ are summarized in Table 2. 
Table 2 Low impact development (LID) ratio for scenarios A2 and A3

\begin{tabular}{|c|c|c|c|c|}
\hline \multirow{4}{*}{ Location } & \multicolumn{4}{|c|}{$\%$ Allocation } \\
\hline & \multicolumn{2}{|c|}{ Scenario A2 } & \multicolumn{2}{|c|}{ Scenario A3 } \\
\hline & LID area & Investment & LID area & Investment \\
\hline & ratio & percentage & ratio & percentage \\
\hline \multicolumn{5}{|l|}{ Catchment } \\
\hline & $47.59 \%$ & $61.04 \%$ & $22.53 \%$ & $28.90 \%$ \\
\hline \multicolumn{5}{|l|}{$\mathrm{L}$} \\
\hline \multicolumn{5}{|l|}{ Catchment } \\
\hline & $18.09 \%$ & $13.40 \%$ & $54.57 \%$ & $40.44 \%$ \\
\hline \multicolumn{5}{|l|}{$\mathrm{JN}$} \\
\hline \multicolumn{5}{|l|}{ Catchment } \\
\hline & $18.84 \%$ & $15.96 \%$ & $13.35 \%$ & $11.32 \%$ \\
\hline \multicolumn{5}{|l|}{$\mathrm{D}$} \\
\hline \multicolumn{5}{|l|}{ Catchment } \\
\hline & $7.64 \%$ & $9.60 \%$ & $15.42 \%$ & $19.34 \%$ \\
\hline DS & & & & \\
\hline
\end{tabular}

\subsection{Efficacy evaluation of adaptive LID measures}

To alleviate the urban flooding under different return periods, LID measures were determined for two scenarios (Fig. 9). The results show that LID effects vary with the return period of stormwater events. Specifically, the peak inundation volume reduction rate increases when the storm events are less intense. Compared with the A1 scenario, LID measures can reduce the peak inundation volume by $11.42 \%-25.04 \%, 24.59 \%-$ $32.48 \%$, respectively. In general, the efficiency of the hazard inundation volume reduction was as follows: scenario $\mathrm{A} 1<$ scenario $\mathrm{A} 2<$ scenario $\mathrm{A} 3$. 
A3 was higher than that of scenario A2. At the return periods of 2 years, 10 years, and $13.17 \%$, respectively, as compared with those of scenario A2. This is because with increasing design return period, the $R I$ increases, thereby increasing the regional inundation volume transfer ratio, which makes the flood source area control strategy more effective. This validates the effectiveness of the proposed framework.

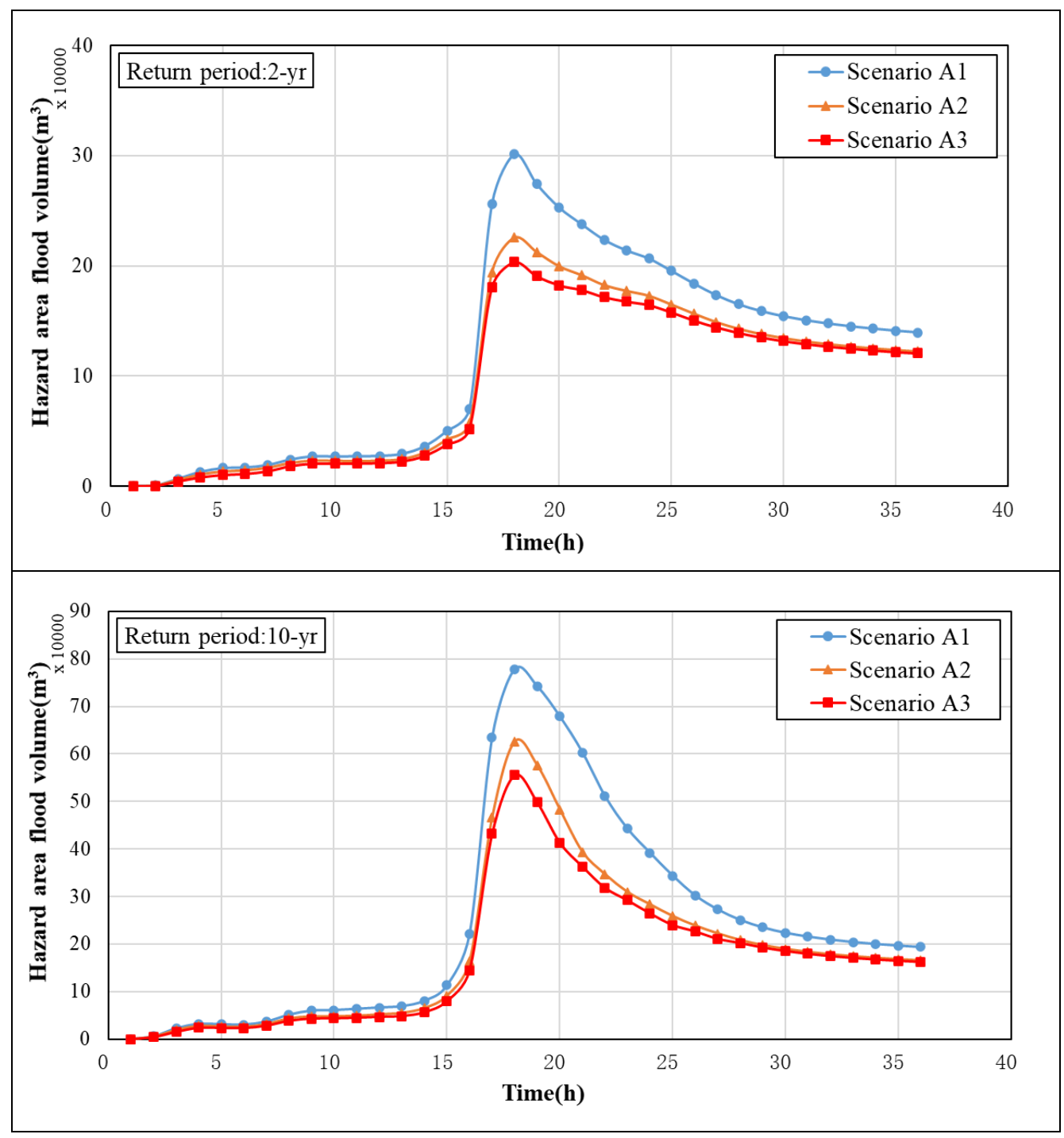




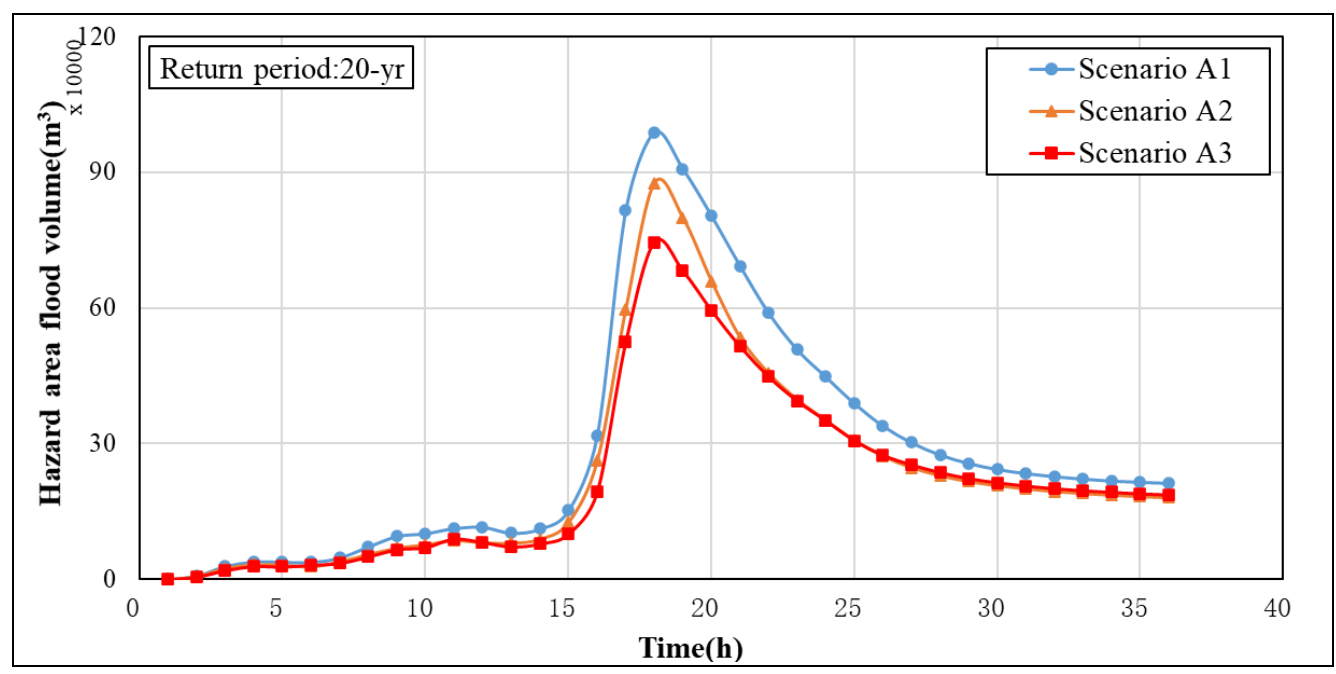

Fig. 9 Comparative diagram of inundation volumes in three scenarios during combined storm tide and heavy rainfall

\section{Conclusions}

In this study, a simulation-optimization framework for designing LID strategies that utilizes the source tracking technique was proposed. The framework was successfully applied to Haikou City, and the results revealed the importance of the spatial connectivity of LID measures. The main conclusions are as follows:

- The framework first introduced the source tracking method in LID measure spatial arrangement, based on source tracking data in order to distinguish the source of the hazard area inundation volume and determine an LID allocation strategy according to the flood contribution ratio of the flood source area. These findings are especially important for highlighting flood source control to mitigate urban flood hazards.

- To quantify regional relevance, a regional relevance index $(R I)$ was developed to determine the importance of inundation volume transfer between flood source and hazard areas during urban flood mitigation. These results show that the regional inundation volume transfer greatly impacts the efficacy of LID measures. 
Furthermore, different disaster-causing factors have different degrees of impact on the regional correlation indicators. Moreover, compared with the tide level, the $R I$ is more sensitive to rainfall volume, wherein the greater the rainfall intensity, the higher the $R I$ in different regions.

- For different design return period storm events, the effectiveness of the LID measures is better for low return periods than moderate and heavy stormwater

Ethical Approval All work is compliance with Ethical Standards.

Consent to Participate Not applicable.

Consent to Publish The authors are indeed informed and agree to publish. (No. 51679156).

\section{References}

532 Ahiablame L, Shakya R (2016) Modeling flood reduction effects of low impact 
development at a watershed scale. J Environ Manage 171:81-91. https://doi.org/10.1016/j.jenvman.2016.01.036

Bakhshipour AE, Dittmer U, Haghighi A, Nowak W (2019) Hybrid green-blue-gray decentralized urban drainage systems design, a simulation-optimization $\begin{array}{lllll}\text { framework. } & \mathrm{J} & \text { Environ } & \text { Manage } & 249\end{array}$ https://doi.org/10.1016/j.jenvman.2019.109364

Becker P (2018) Dependence, trust, and influence of external actors on municipal urban flood risk mitigation: the case of Lomma Municipality, Sweden. Int J Disast Risk Re 31:1004-1012. https://doi.org/10.1016/j.ijdrr.2018.09.005

Bentley ML, Ashley WS, Stallins JA (2010) Climatological radar delineation of urban convection for Atlanta, Georgia. Int J Climatol 30:1589-1594. https://doi.org/10.1002/joc.2020

Cano OM, Barkdoll BD (2017) Multiobjective, Socioeconomic, Boundary-Emanating, Nearest Distance Algorithm for Stormwater Low-Impact BMP Selection and Placement. J Water Resour. Plann Manage 143: 05016013. https://10.1061/(ASCE)WR.1943-5452.0000726

CHI (Computational Hydraulics Int) (2014). PCSWMM- Advanced Modeling of Stormwater, Wastewater and Watershed Systems Since 1984. Available at: http://www.pcswmm.com/

Cristiano E, Ten Veldhuis MC, Wright DB, Smith JA, Nick VDG (2019) The influence of rainfall and catchment critical scales on urban hydrological response sensitivity. Water Resour Res 55:3375-3390. https://doi.org/10.1029/2018WR024143 
Duan HF, Li F, Yan HX (2016) Multi-Objective Optimal Design of Detention Tanks in the Urban Stormwater Drainage System: LID Implementation and Analysis. Water Resour Manag 30: 4638-4648. https://doi.org/10.1007/s11269-016-1444-1

Fletcher TD, Shuster W, Hunt WF, Ashley R, Butler D, Arthur S, Trowsdale S (2014) SUDS, LID, BMPs, WSUD and more-the evolution and application of terminology surrounding urban drainage. Urban Water J 12:525542.https://doi.org/10.1080/1573062X.2014.916314

Gilroy KL, McCuen RH (2009), Spatio-temporal effects of low impact development practices. J Hydrol 367:228-236. https://doi.org/10.1016/j.jhydrol.2009.01.008

Hallegatte S, Ranger N, Mestre O, Dumas P, Corfee-Morlot J, Herweijer C, Muir-Wood R (2011) Assessing climate change impacts, sea level rise and storm surge risk in port cities: a case study on Copenhagen. Clim Change 104:113-137. https://doi.org/10.1007/s10584-010-9978-3

Hood MJ, Clausen JC, Warner GS (2010) Comparison of Stormwater Lag Times for Low Impact and Traditional Residential Development. J Am Water Resour As 43:1036-1046. https://doi.org/ 10.1111/j.1752-1688.2007.00085.x

Huang CL, Hsu NS, Liu HJ, Huang YH (2018) Optimization of low impact development layout designs for megacity flood mitigation. J Hydrol 564: 542-558. https://10.1016/j.jhydrol.2018.07.044

Liang CY, You GJY, Lee HY (2019), Investigating the effectiveness and optimal spatial arrangement of low-impact development facilities. J Hydrol 577: 124008. https://doi.org/10.1016/j.jhydrol.2019.124008 
Liu YZ, Theller LO, Pijanowski BC, Engel BA (2016) Optimal selection and placement of green infrastructure to reduce impacts of land use change and climate change on hydrology and water quality: an application to the Trail Creek Watershed Indiana. Sci Total

Environ 553: 149-163. https://doi.org/10.1016/j.scitotenv.2016.02.116

Liu. W, Chen WP, Peng C (2014) Assessing the effectiveness of green infrastructures on urban flooding reduction: A community scale study. Ecol Model 291:6-14. https://doi.org/10.1016/j.ecolmodel.2014.07.012

Ranger N, Hallegatte S, Bhattacharya S, Bachu M, Priya S, Dhore K, Rafique F, Mathur P, Naville N, Henriet F, Henriet F, Herweijer C, Pohit SJ, Corfee-Morlot J (2011) An assessment of the potential impact of climate change on flood risk in Mumbai. Clim Change 104:139-167. https://doi.org/10.1007/s10584-010-9979-2

Salvadore E, Bronders J, Batelaan O (2015) Hydrological modelling of urbanized catchments: a review and future directions. J Hydrol 529:62-81. https://doi.org/10.1016/j.jhydrol.2015.06.028

Tang S, Luo W, Jia Z, Liu W, Li S, Wu Y (2016) Evaluating Retention Capacity of Infiltration Rain Gardens and Their Potential Effect on Urban Stormwater Management in the Sub-Humid Loess Region of China. Water Resour Manag 30: 983-1000. https://doi.org/10.1007/s11269-015-1206-5

Tillinghast E, Hunt WF, Jennings GD, D'Arconte P (2012) Increasing stream geomorphic stability using storm water control measures in a densely urbanized watershed. J Hydrol Eng 17:1381-1388. https://doi.org/10.1061/(ASCE)HE.1943- 
600

601

602

603

604

605

606

607

608

609

610

611

612

613

614

615

616

Urich C, Rauch W (2014) Exploring critical pathways for urban water management to identify robust strategies under deep uncertainties. Water Res 66: 374-389. https://doi.org/10.1016/j.watres.2014.08.020

Valizadeh N, Shamseldin, AY, Wotherspoon L (2019) Quantification of the hy draulic dimension of stormwater management system resilience to flooding. Water Resour Manag 33: 4417-4429. https://doi.org/10.1007/s11269-019-023 $61-1$

Wang YT, Meng FL, Liu HX, Zhang C, Fu GT (2019) Assessing catchment s cale flood resilience of urban areas using a grid cell based metric. Water Res 163:114852. https://doi.org/10.1016/j.watres.2019.114852

Willems P, Arnbjerg-Nielsen K, Olsson J, Nguyen VTV (2012) Climate change impact assessment on urban rainfall extremes and urban drainage: methods and shortcomings.

Atmos.

Res.

103:106-118. https://doi.org/10.1016/j.atmosres.2011.04.003

Williams ES, Wise WR (2006) Hydrologic Impacts of Alternative Approaches to Storm Water Management and Land Development. J Am Water Resour As 42:443-455. https://doi.org/10.1111/j.1752-1688.2006.tb03849.x

Winsemius HC, Aerts JCJH, van Beek, LPH, Bierkens MFP, Bouwman A, Jongman B, Kwadijk JCJ, Ligtvoet W, Lucas PL, van Vuuren DP, Ward, PJ (2016) Global drivers of future river flood risk. Nat Clim Change 6:381-385. https://doi.org/10.1038/nclimate2893 
621

622

623

624

625

626

627

628

629

630

631

632

Xu HS, Ma C, Lian JJ, Xu K, Chaima E (2018) Urban flooding risk assessment based on an integrated k-means cluster algorithm and improved entropy weight method in the region of Haikou, China. J Hydrol 563:975-986. https://10.1016/j.jhydrol.2018.06.060

Xu T, Jia HF, Wang Z, Mao XH, Xu CQ (2017) SWMM-based methodology for blockscale LID-BMPs planning based on site-scale multi-objective optimization: a case study in Tianjin. Front Env Sci Eng 11: 48-59. https://doi.org/10.1007/s11783017-0934-6

Zischg J, Goncalves MLR, Bacchin TK, Leonhardt G et al (2017) Info-Gap robustness pathway method for transitioning of urban drainage systems under deep $\begin{array}{llll}\text { uncertainties. } & \text { Water } & \text { Sci } & \text { Technol }\end{array}$ https://doi.org/10.2166/wst.2017.320 


\section{Figures}

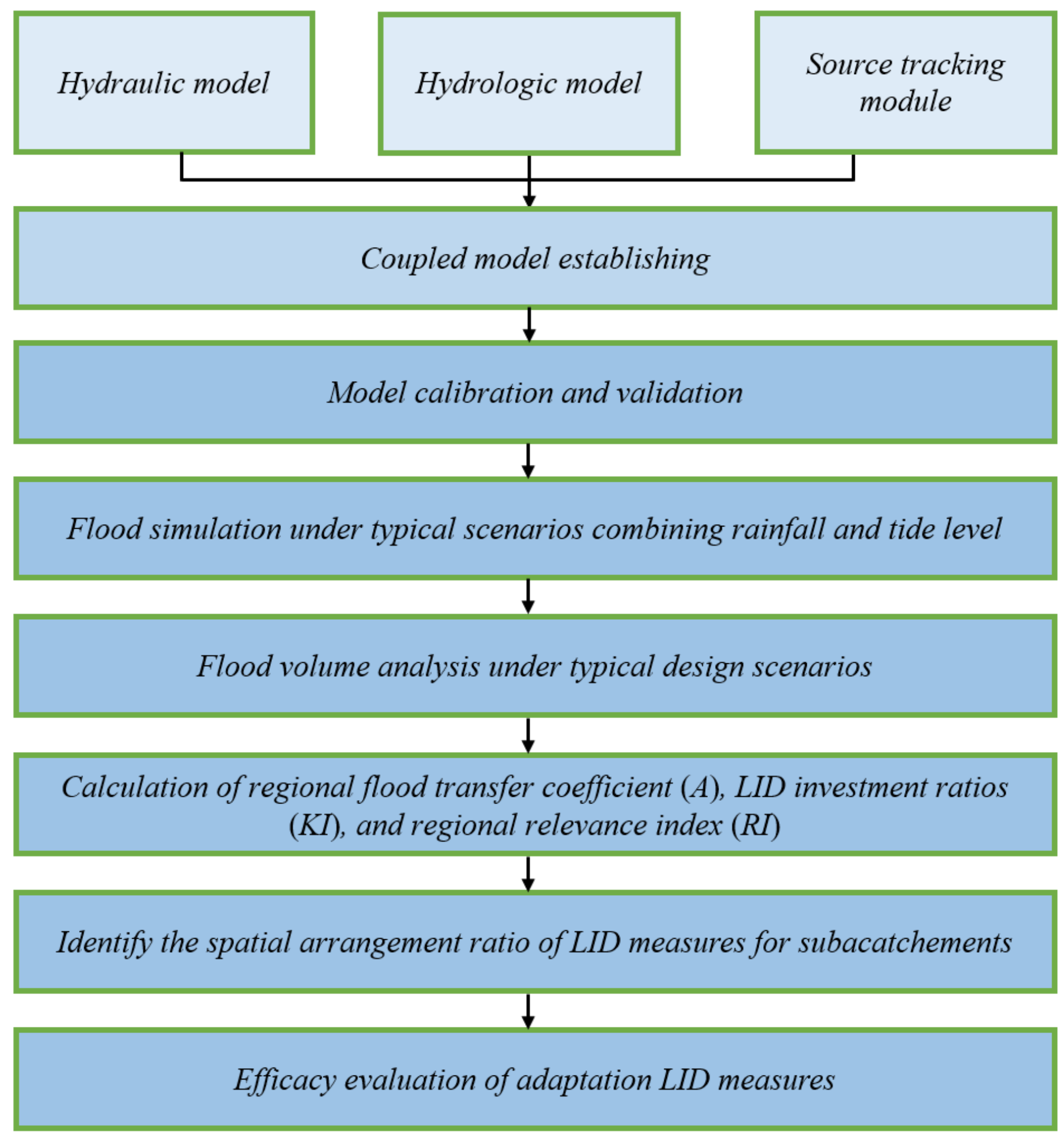

\section{Figure 1}

Optimal framework of spatial arrangement of low impact development (LID) measures based on source tracking for urban flood mitigation 


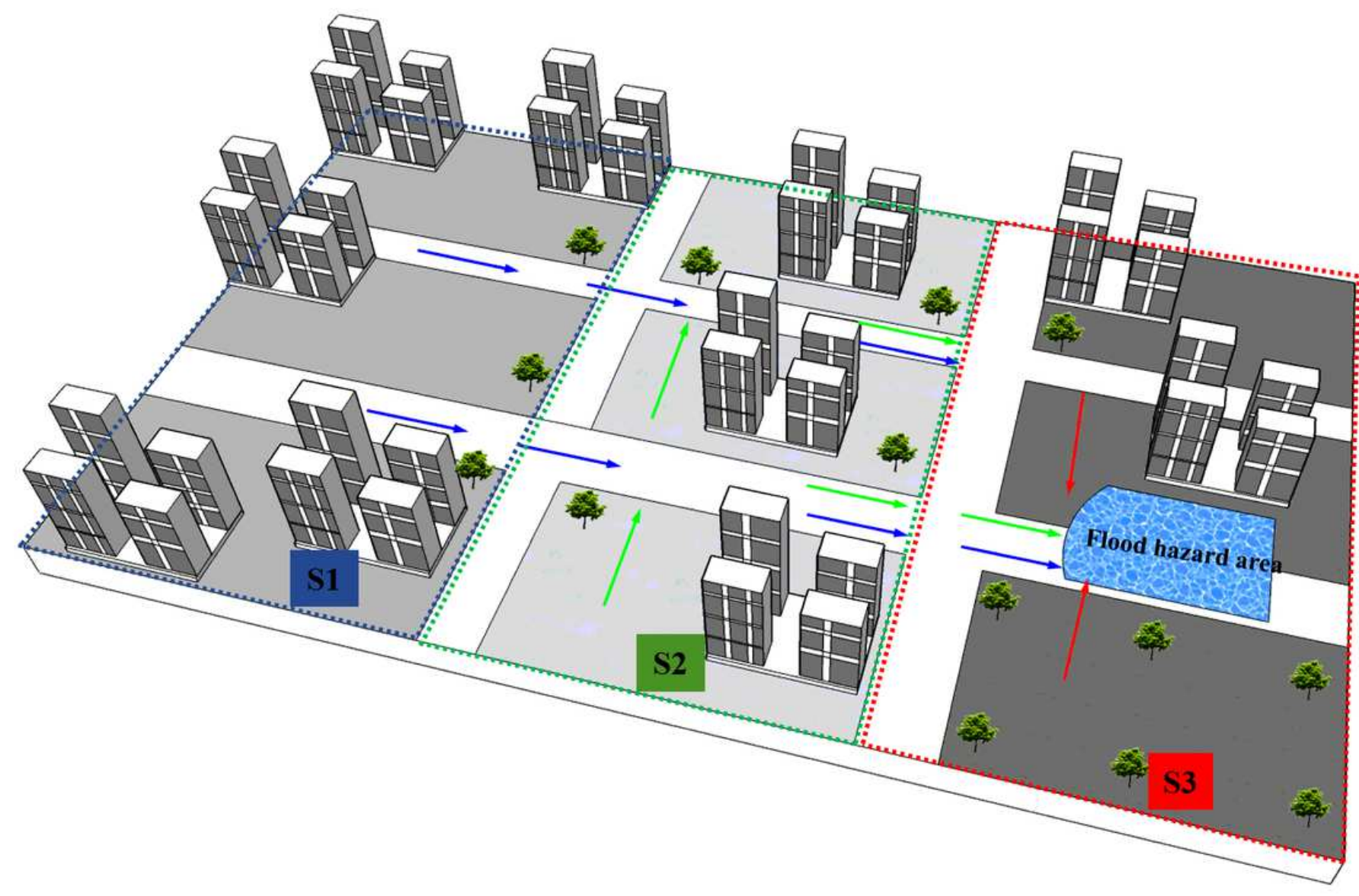

Figure 2

Schematic diagram of the runoff source tracking process in urban watershed

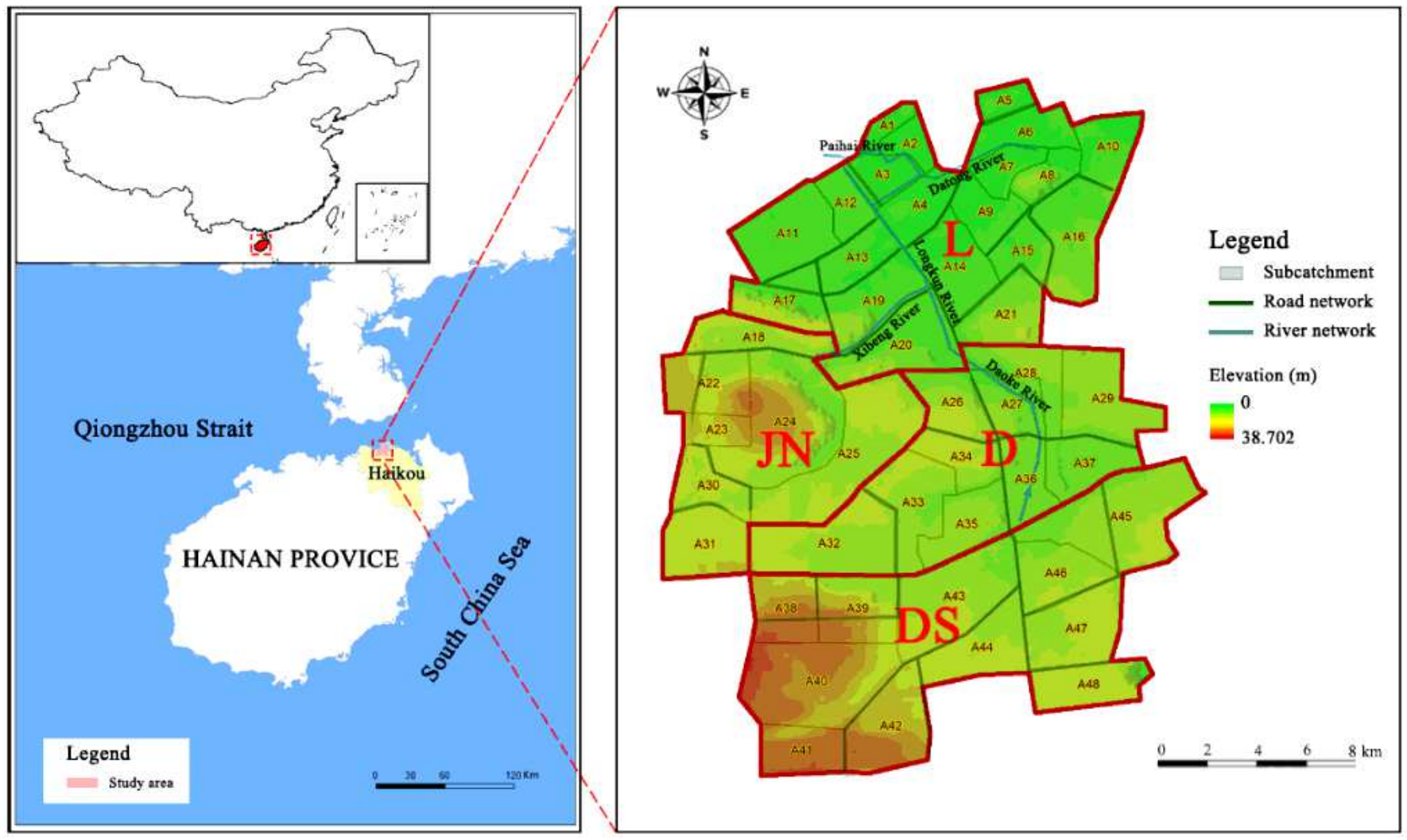




\section{Figure 3}

Study area and sewer system distribution Note: The designations employed and the presentation of the material on this map do not imply the expression of any opinion whatsoever on the part of Research Square concerning the legal status of any country, territory, city or area or of its authorities, or concerning the delimitation of its frontiers or boundaries. This map has been provided by the authors.

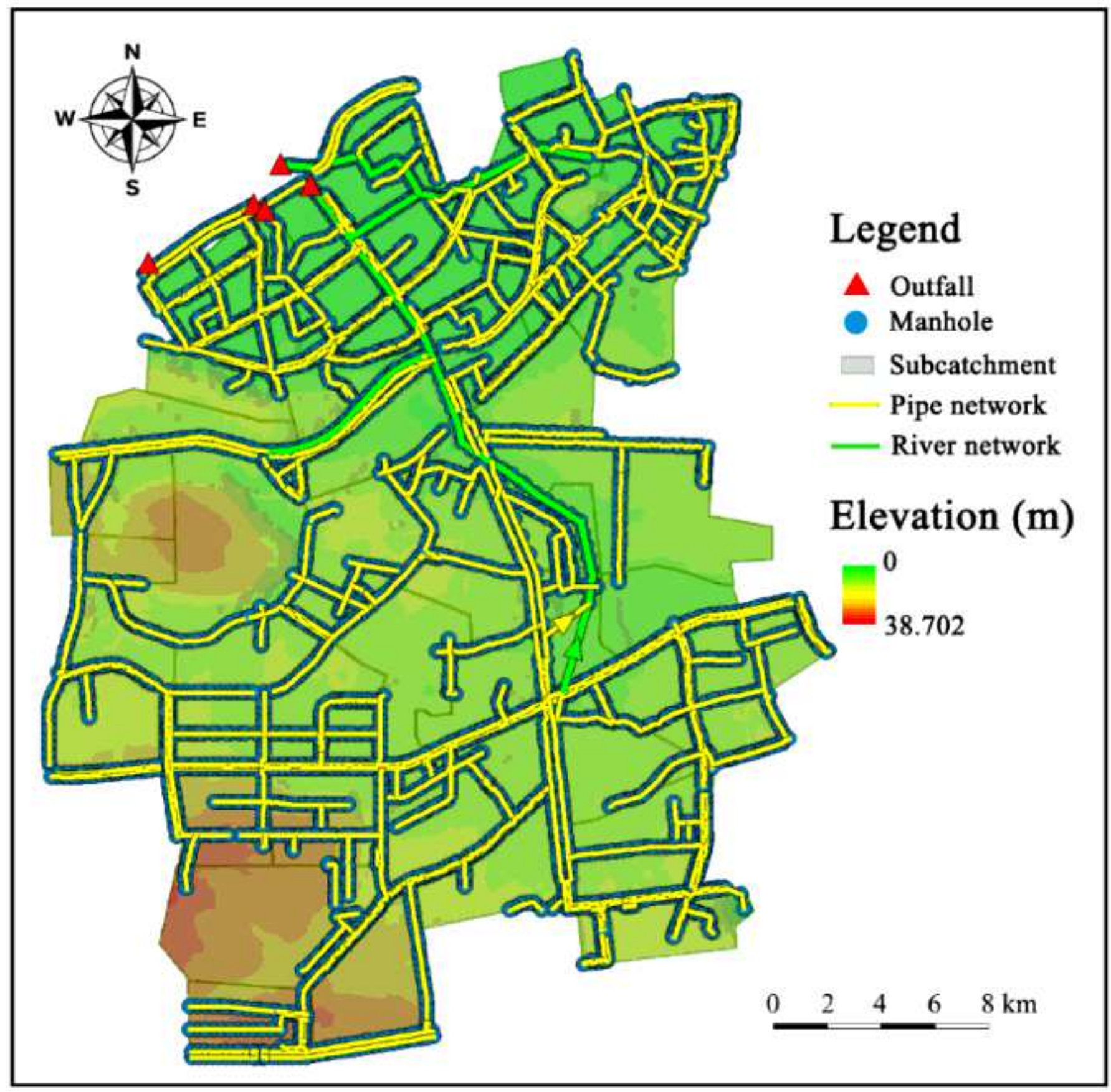

Figure 4

Urban flood model establishing of study area based on the PCSWMM Note: The designations employed and the presentation of the material on this map do not imply the expression of any opinion whatsoever on the part of Research Square concerning the legal status of any country, territory, city or area or of its 

the authors.

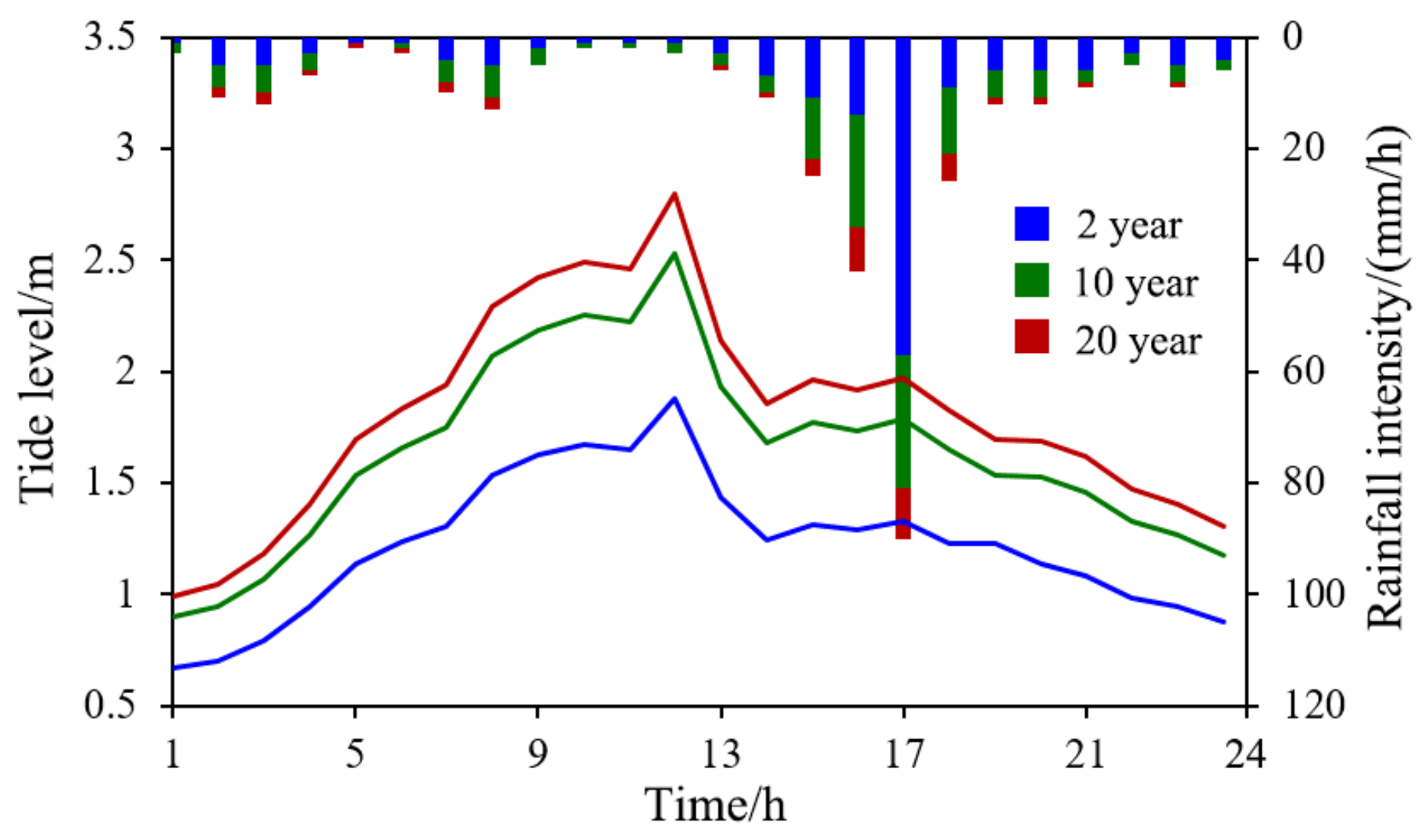

Figure 5

Distribution of design rainfall and tide level 


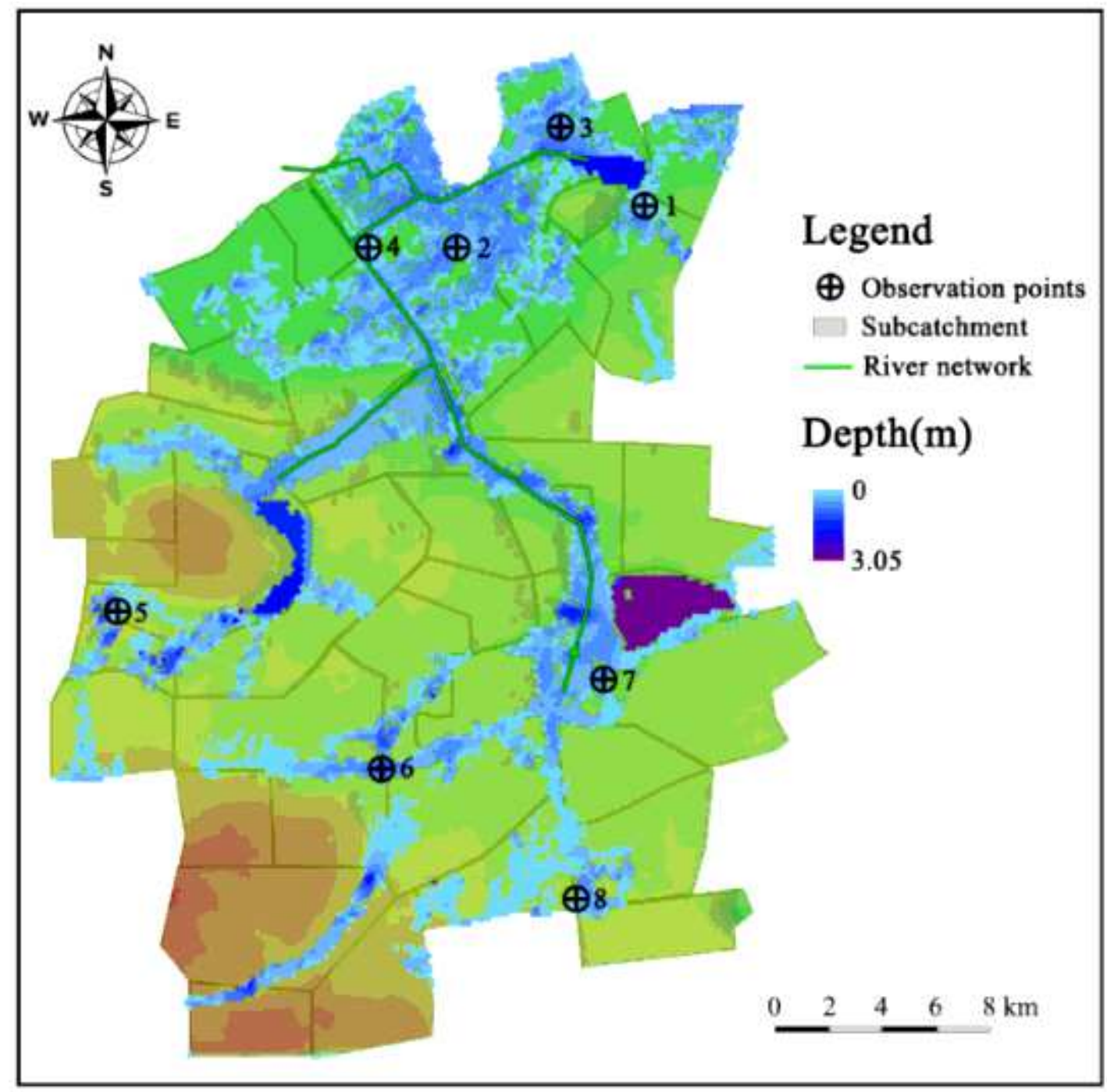

Figure 6

Simulation flood during the "Rammasun" typhoon storm event in July 2014 Note: The designations employed and the presentation of the material on this map do not imply the expression of any opinion whatsoever on the part of Research Square concerning the legal status of any country, territory, city or area or of its authorities, or concerning the delimitation of its frontiers or boundaries. This map has been provided by the authors. 


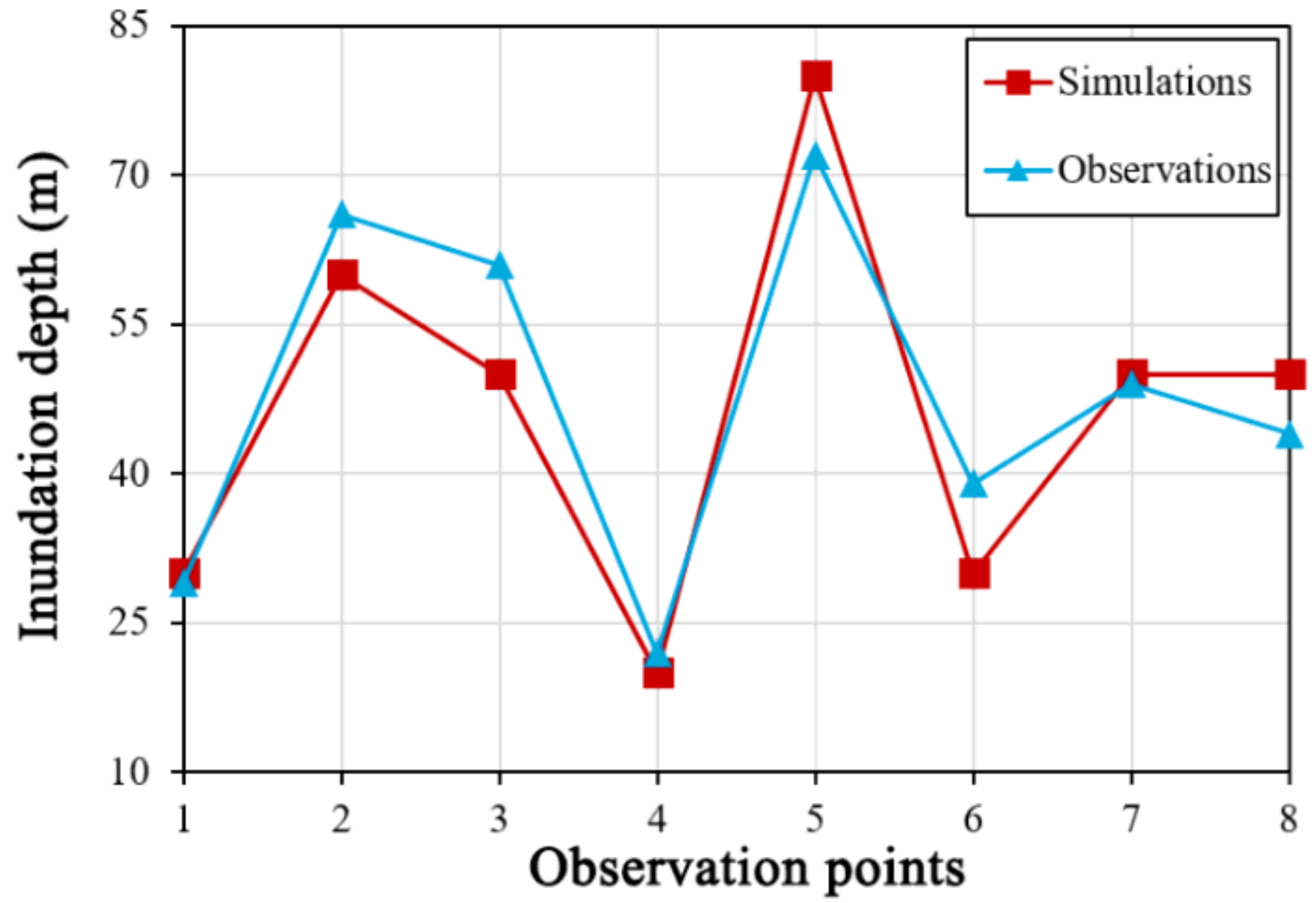

Figure 7

Calibration of the PCSWMM 


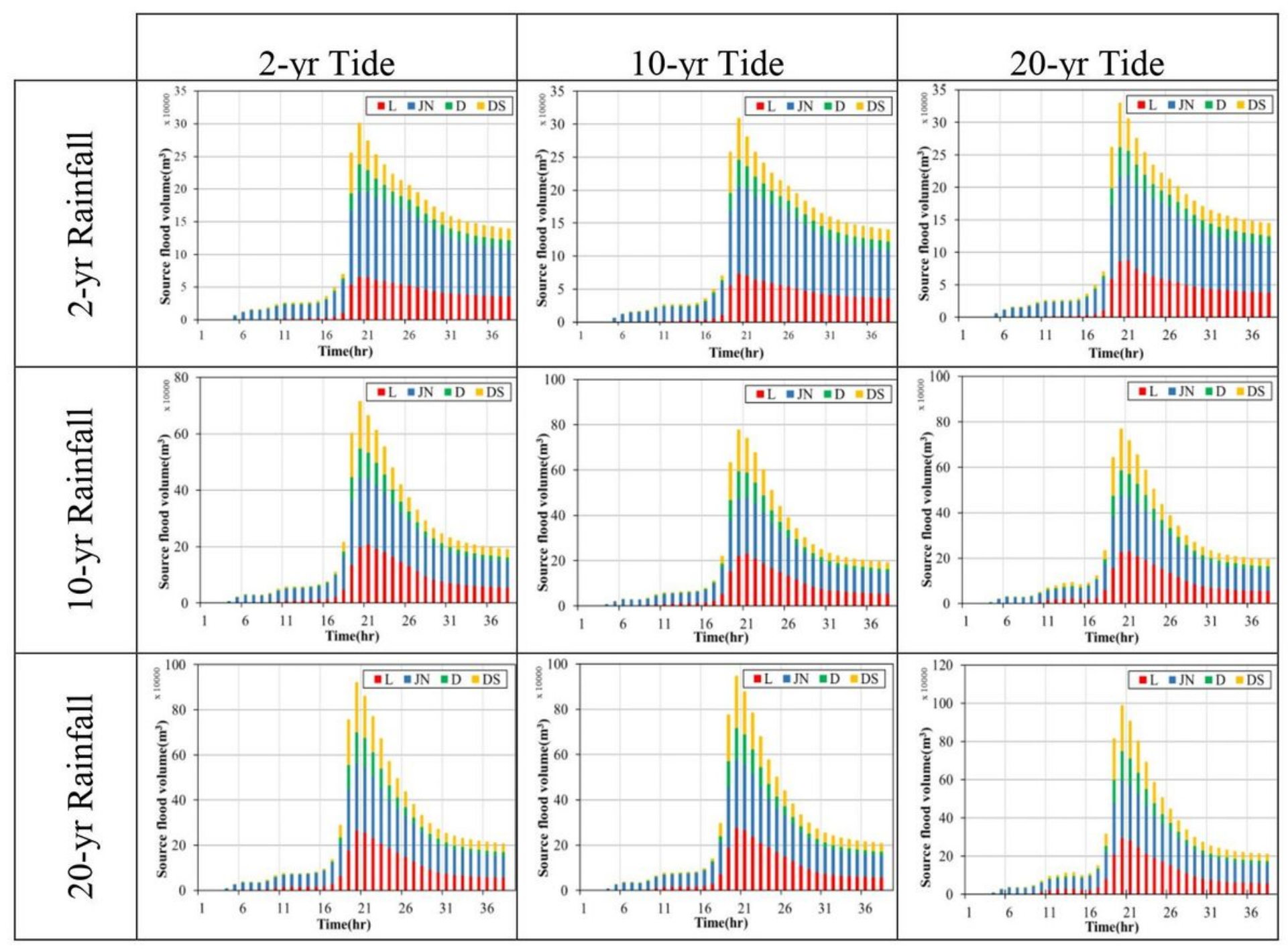

Figure 8

Diagram of flood source area inundation volume contribution to hazard area under the combined impact of storm tides and heavy rainfall 

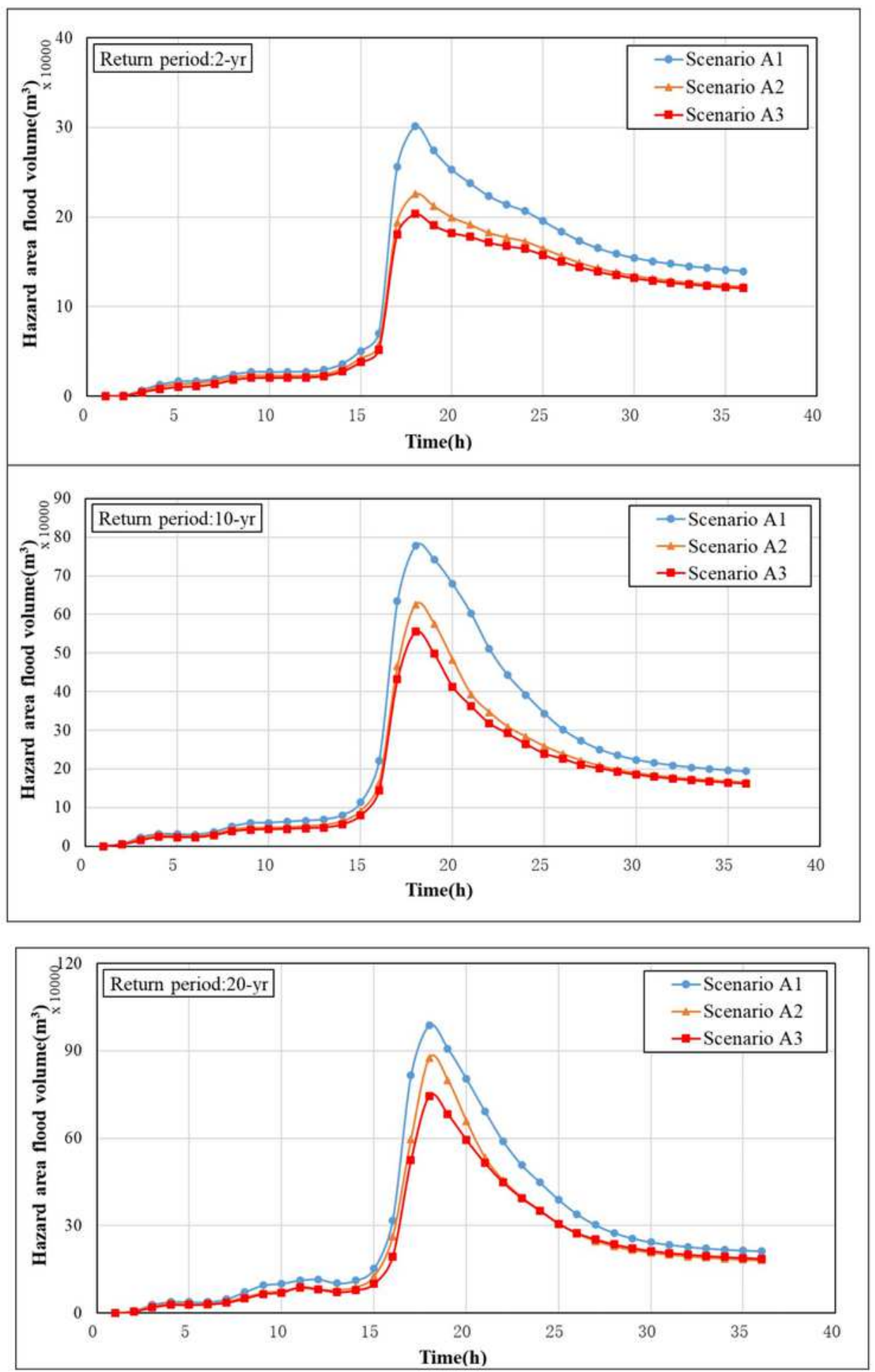

\section{Figure 9}

Comparative diagram of inundation volumes in three scenarios during combined storm tide and heavy rainfall 